\title{
Energy Integration on a Gasoline Engine for Efficiency Improvement
}

\author{
Z. Dimitrova *, F. Maréchal \\ Ecole Polytechnique Fédérale de Lausanne, Lausanne, Switzerland \\ E-mail: zlatina.dimitrova@epfl.ch
}

Received 27 May 2016, Revised 18 January 2017, Accepted 12 April 2017

\begin{abstract}
The internal combustion engines are the most applied energy converters in the passenger cars. In order to increase their efficiency, energy integration techniques are used to recover the waste heat. An adapted methodology is required to design the Organic Rankine Cycle (ORC) as a waste heat recovery technology and to test the influence of the external temperature on its efficiency. The idea is to clusterize the external temperature profile on typical external temperature multi-periods. The energy system design is then tested on these typical multi-periods. In this article the methodology is applied on a vehicle with a small gasoline engine, in order to define the energy integrated configuration of the vehicle and to estimate the cost of the additional equipment. The performances indicators of the energy integration technology of the internal combustion engine is analysed and discussed, according to the multi-periods. The energy recovery potential of a single stage ORC for a small gasoline engine is assessed for different temperature profiles. The ORC equipment is simultaneously pre sized and its cost is estimated. The highest powertrain efficiency improvement due to the waste heat recovery for a small gasoline engine is estimated as $7 \%$.
\end{abstract}

Keywords: Energy integration; engine efficiency; multi-periods; Rankine cycle.

\section{Introduction}

The internal combustion engines are the most applied energy converters in the passenger cars. Their main energy service is to insure the vehicle propulsion. The energy services delivered in a vehicle are the mobility, the comfort and the safety. Orders of magnitude for efficiencies and energy balances of internal combustion engines are given in [1]. The heat dissipated in the cooling liquids and the exhaust gases of the engine can be used to heat the cabin, or to be converted in electricity or cooling.

Several concepts for the engine heat losses recovery exist in the literature. Liu et al. proposed comparison and analysis of engine exhaust gas energy recovery potential through various bottom cycles in [2]. The study included direct recovery means through exhaust gas expansion, such as secondary expansion, and indirect recovery means through heat transfer, such as Rankine steam cycle, Brayton air cycle, etc. The conclusion is that the Rankine cycle presents the best heat recovery potential and the largest application range. Bari and Hossein stated in [3] that the exhaust heat from diesel engines can be an important heat source to provide additional power using a separate Rankine Cycle. They conduct experiments and found that $16 \%$ of additional net power output can be found on a diesel engine. An additional idea was to use also the low and the medium temperature heat domain for the recovery and so the organic fluids are introduced as working fluids for the Rankine cycles. For example, Sprouse and Depik [4] reviewed the use of ORC for ICE exhaust heat recovery. The introduction of organic fluids proposes major choice of working fluids impacting the performance indicators of the Rankine cycle. Jung et al. studied in [5] the selection of appropriate fluids for the Rankine cycle used for exhaust gases heat recovery in heavy- duty series hybrid vehicles. $\mathrm{R} 245$ is proposed as working fluid.

$\mathrm{Li}$ studied in [6] several working fluid candidates for various ORC applications based on the heat source temperature domains have been investigated for the thermal efficiency, exergy destruction rate and mass flow rate under different ORC configurations.

Quoilin et al. applied a thermo-economic optimization of an ORC for small scale industrial applications in [7]. They stated that the optimum of each performance indicator- net power, thermal and exergetic efficiency of the ORC bellows to different operating points. They also correlate the cost on the ORC components size.

The needs of efficiency improvement of the vehicle energy systems require finding innovative solutions during the design process, integrating all vehicle services and energy requirement on a vehicle system level. The following literature review illustrates the application of the energy integration methodology for vehicular applications. In [8] the boundaries of the energy system are extended to the powertrain and the cabin and the requirements for mobility and comfort are integrated. The energy integration methodology is applied on a hybrid electric vehicle energy system, and is studied for adapted dynamic profile, represented by characteristic clustered operating points. The concept of hybrid pneumatic powertrain and ORC is evaluated in [9] on different driving cycles and the 
economic analysis of the customer mobility is done, according to his drive profile. In this article an innovative methodology using energy integration and multi-objective optimization is applied for the design of the organic Rankine cycle loop. The selection of the ORC design is based on techno-economic indicators and by using a qualification utility function for the population of solutions on the Pareto curve.

The process optimization proposes a structured methodology to identify, characterize and quantify the waste heat of a system. The process integration (PI) methodology dates back to the 1970s and the first developments are in the heat integration [10]. The PI is deployed in the oil, chemical and energy industry [10]. Linnhoff in [11] illustrates the pinch method for heat exchangers design and heat integration. Some developments in the PI applied to the chemical engineering research are summarized in [12]. In this article the efficiency improvement of the hybrid electric vehicle powertrain through PI is researched. The energy integration methodology is based on the heat integration, which targets the maximum heat recovery in the energy system. The approach consists in mapping all hot and cold streams in the system and displays the heat composite curve. The methodology gives the advantage to provide a global picture of the heat exchanges in the system. It also provides the MER - minimum energy requirement. MER is the minimum amount to be introduced or extracted from the system by means of cold or hot utilities. As a result, the utilities are selected and sized. Process integration techniques and energy analysis are used to measure the useful potential of the waste heat [13].

In the present study, the boundaries of the energy system are extended including the comfort service. The application is done on a vehicle propelled with a small gasoline engine. In an internal combustion engine, the chemical energy is converted to heat and then to mechanical energy. This allows bringing sensitivity analysis to the energy integration on real usage temperature profiles. Another contribution of the article is to propose an adapted cost model for the energy integration for small scale installations from 5 to $15 \mathrm{~kW}$ of net power output and estimation of the fuel consumption reduction due to the waste heat recovery.

In this article the energy integration methodology is applied on a dynamic energy system - the vehicles. According to the ambient temperature and the requirement for comfort (cooling or heating), defined by clustering of the external temperature data, the heat losses can be used to heat the cabin or to be converted to electricity or cold air, using utilities cycles to close the energy balance and evaluate the cost of the heat recovery equipment. The ORC is selected as utility for heat recovery and its size and performances are studied for the different temperature clusters (multi-periods). The heat recovery is studied on a small gasoline engine. The economic models are also defined for the range of small scale ORC installations. Finally the efficiency improvement is assessed for a middle size vehicle equipped with a small gasoline engine and ORC installation for heat recovery. The novelty of the article is to propose a methodology for integrated mobility and comfort services on vehicular applications. In this method the comfort demand profiles are clustered on stationary typical multi-periods.

\section{Methodology}

\subsection{Energy Integration}

The energy integration in combination with multiobjective techniques and multi-period perspectives is recently applied to grid non autonomous (grid related) energy systems and uses single optimization model with MILP [14]. In this article the energy integration methodology is applied on the vehicle powertrain and the cabin. The superstructure of the calculation tool OSMOSE is proposed as an option. The general computational framework of OSMOSE (Figure 1) has already been described in [15] for thermo-economic evaluation and optimization of the thermo-chemical conversion of biomass into methanol and used for several industrial applications. The methodology is adapted and explained for vehicle applications in [16] for electric vehicles and in [17] for hybrid electric vehicles. The optimizer in OSMOSE is based on a genetic algorithm.

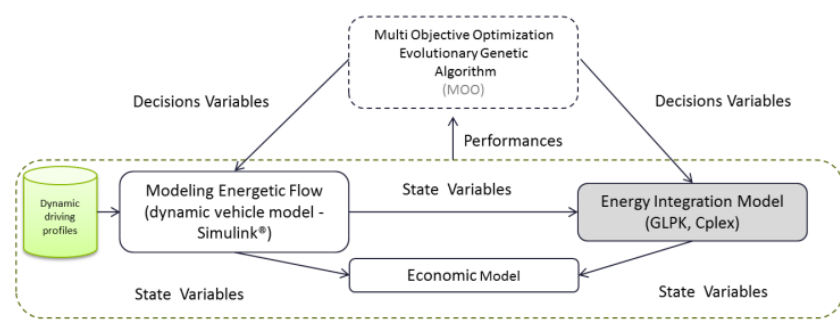

Figure 1. Architecture of the multi-objective optimization tool, OSMOSE.

The energy integration is a slave optimization part of the OSMOSE Superstructure and in this article the Energy integration model is studied in particularly. The energy integration calculates the best operating strategy of selected equipment by solving a mixed integer linear model (MILP) (Figure 2). The aim is to minimize the total cost under the energy balance and the heat and power cascade constraints. The input data used in the energy integration includes the values of the master decision variables, the resources, the power dynamic profile and the comfort profile. To do the energy integration optimization multi-periods is needed, reducing the number of variables and the calculation time. Figure 2 illustrates the energy integration steps.

The energy integration is the second stage of the approach and it is a slave optimization based on mixed integer linear programming. The energy integration defines the potential of heat recovery and deduces the choice and the sizing of the adapted utilities. In the energy integration problem the engine and the vehicle cabin are defined as processes exchanging heat between them. The utility system pertinent for energy recovery - the organic Rankine cycle is defined in the energy integration module. In the energy integration the level of temperatures (condensation and evaporation) of the ORC are optimized to obtain the maximal net power output. The optimization is done for each operating point and each working fluid and comfort demand. The outcomes of this optimization are the ORC loop sizing (working fluid flow, sizes of the turbo machines and exchanged heat in the evaporation and the condensation) the efficiency and the net power output.

\subsection{Clustering - Multi Periods and Comfort Demand Profiles}

Typical operating clusters (periods): The centroid cluster $\mathrm{k}$-means algorithm is described in [10], where the typical 


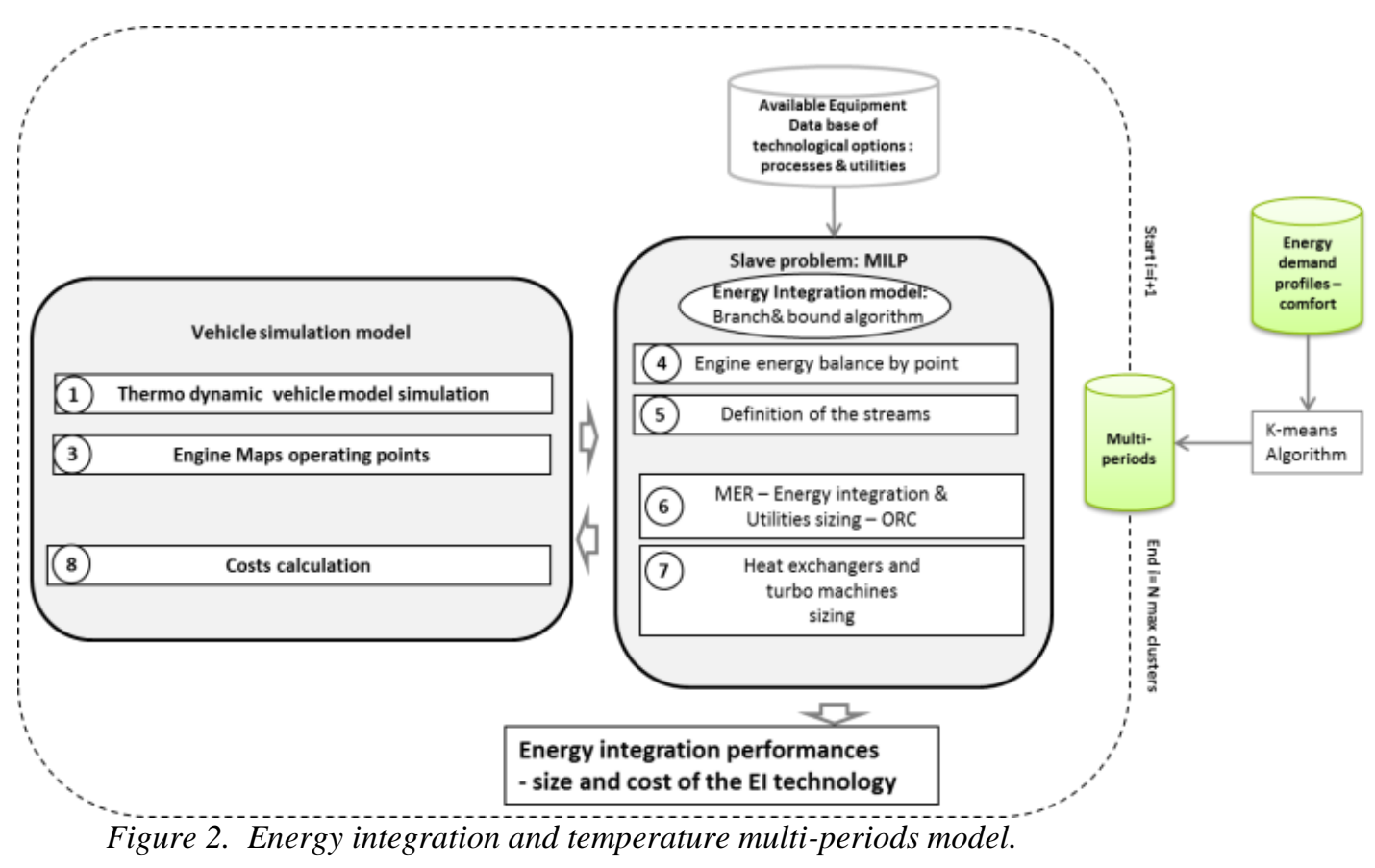

power demand profiles for a district heating network are researched. According to the literature, the hierarchical and partitional algorithm approaches can be found for data analysis. In this article k-means proportional algorithm is used to define the typical temperature periods impacting the comfort demand of the vehicle. The algorithm is illustrated in Figure 3.

1. The data - the ambient temperature is decomposed in $N_{i}$ observations, $N_{a}$ attributes and $N_{g}$ measurements. There is only one attribute, the temperature, so $N_{a}=1$ and 24 hours in day, so $N_{g}$ is equal to 24 . The temperature measurement data are taken from the Lausanne Pully weather station and this for the last 10 years. The data represents 97409 times steps of hourly temperatures for 10 years, from 2004 to 2013. This is determining the size of the observations $N_{i}$.
2. Since the number of optimal clusters $N_{k}$ is unknown, one has to run the k-means algorithm for $N_{k}$ included between 1 and 20 .

3. The number of optimal clusters $N_{k}$ is determined according to the convergence of the performances indicators :

a. C- the average intra clusters distance

b. D- the average inter-clusters distance

c. ESE - the ratio of observed to expected errors

4. Pareto frontiers are drawn for each performance indicator and support the choices of the optimal number of clusters. The decision criterion is reached when the difference between the performance indicator at iteration $k$ and $k+1$ is less than $20 \%$.

5. Extreme temperatures - minimum and maximum are added on $0^{\circ} \mathrm{C}$ and $30^{\circ} \mathrm{C}$, which correspond to the theoretical winter and summer periods.

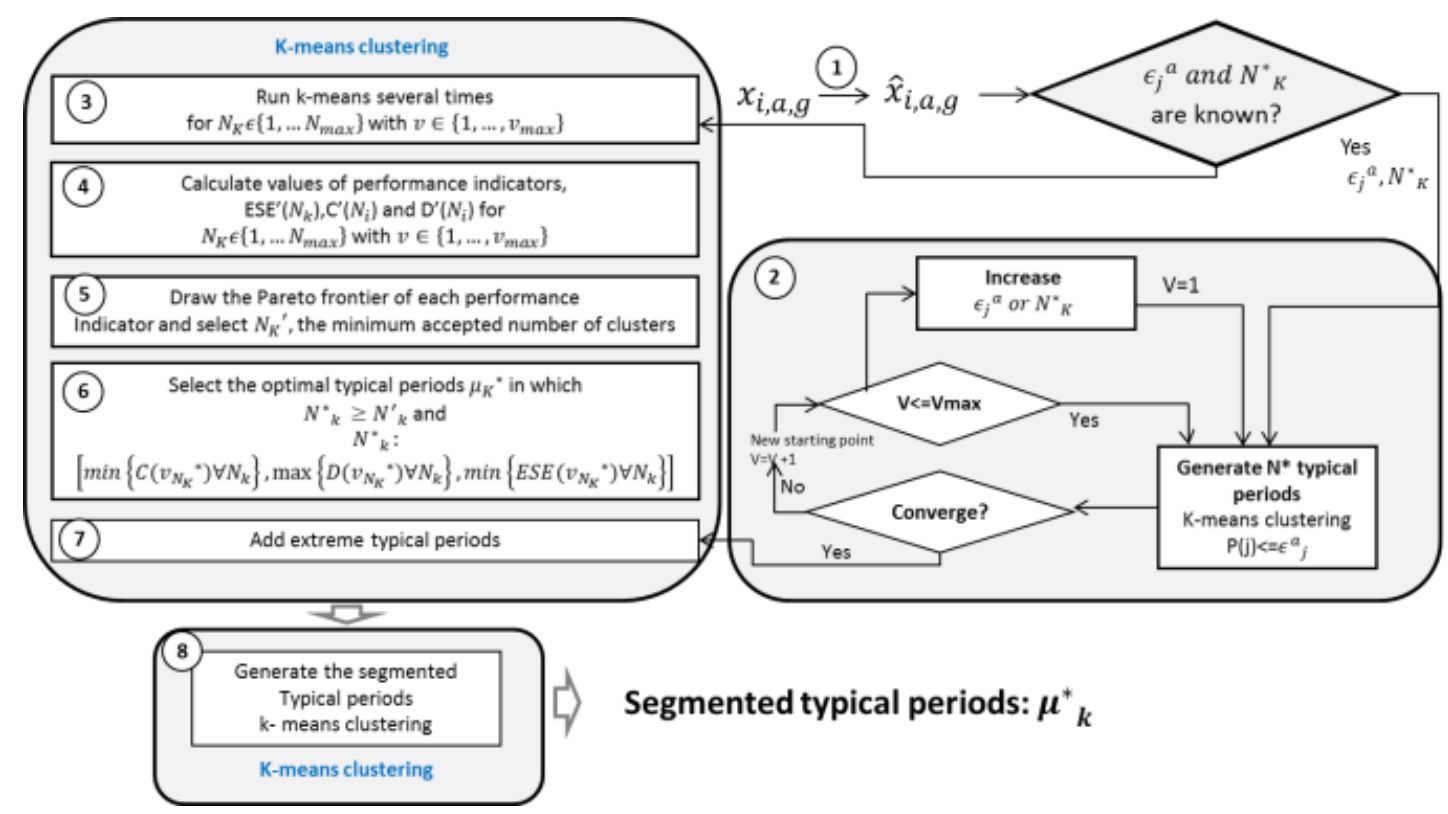

Figure 3. k-means algorithm for clustering. 


\section{Results on Energy Integration and Multi-periods}

\subsection{Clusters Indicators and Temperature Clusters}

The criteria to reach the optimal number of clusters are:

- to minimize the value of $\mathrm{C}$

- $\quad$ to maximize the value of D

- $\quad$ to minimize the value of ESE ratio of observed and expressed error between two iterations should be less than $20 \%$.

Figure 4 illustrates the Paretos of the indicators as a function of the clusters number. $\mathrm{C}$ decreases at each new clusters, because it measures the distance between each cluster. For D, the maximum is reached at 15 clusters. However it seems too high, especially when one observes the other indicators - C, ESE. ESE reaches a minimum for 4 clusters. Therefore, the choice of 4 clusters is accurate, because it minimizes ESE, $\mathrm{C}$ and maximizes $\mathrm{D}$.

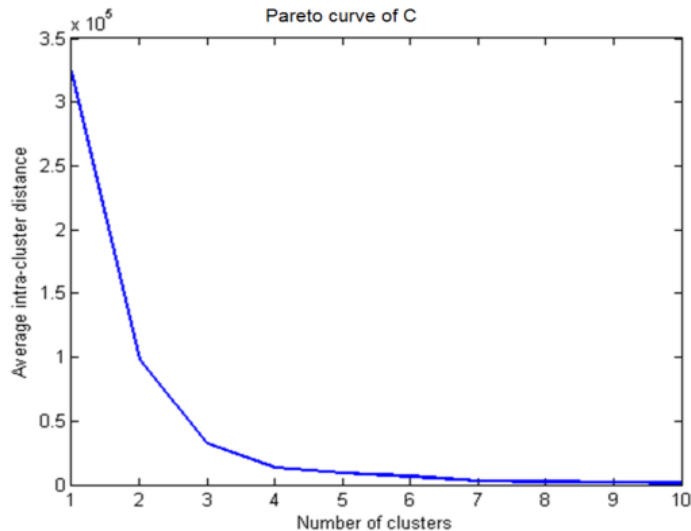

a)

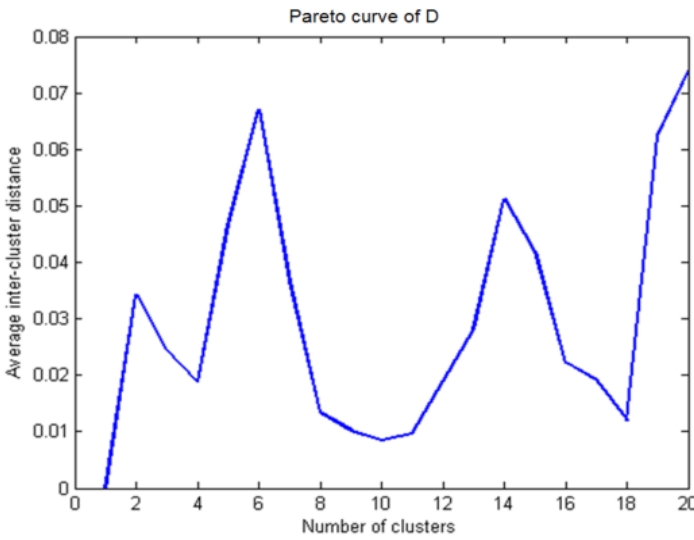

b)

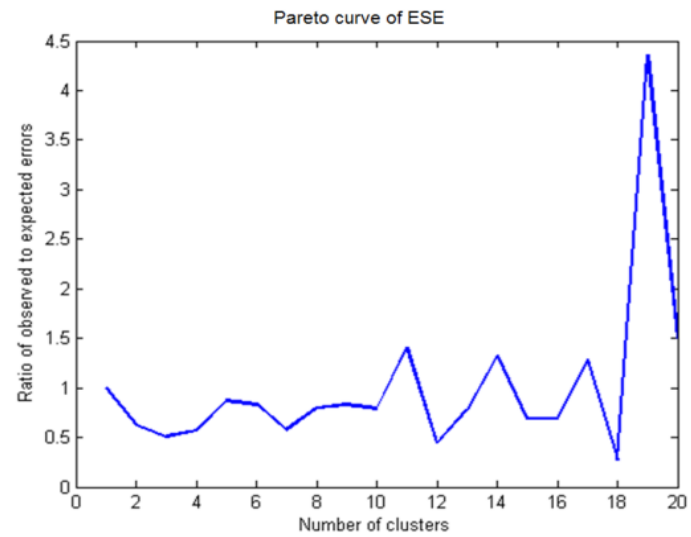

c)

Figure 4. k-means clustering indicators a) intra-cluster distance, $b$ ) inter cluster distance, c) ratio of the observed to expected errors.
The different temperatures of the typical periods are: $T_{1}=0.5{ }^{\circ} \mathrm{C}, T_{2}=8{ }^{\circ} \mathrm{C}, T_{3}=15{ }^{\circ} \mathrm{C} ; T_{4}=23{ }^{\circ} \mathrm{C}$.

The extreme level of $0^{\circ} \mathrm{C}$ and $30^{\circ} \mathrm{C}$ are selected to represent the winter and the summer case. The maximum and the minimum temperatures during the 10 years data (20042013) are $35.6^{\circ} \mathrm{C}$ and $-13.5^{\circ} \mathrm{C}$ (Figure 5).

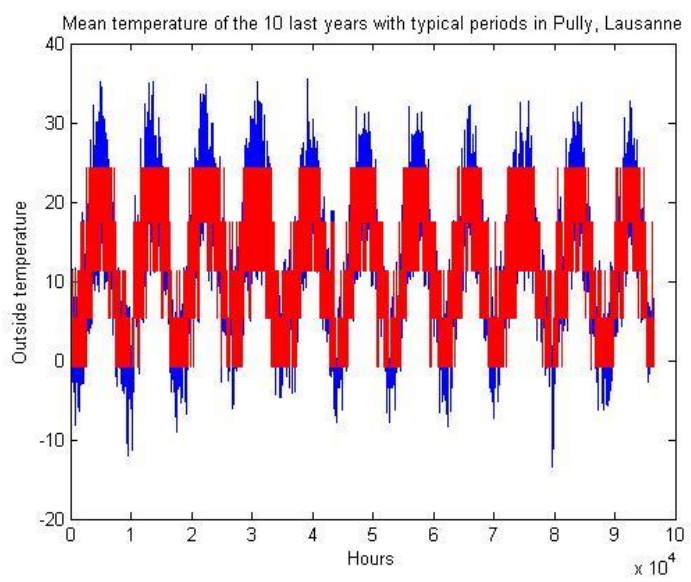

Figure 5. Repartition of the temperature clusters on the last 10 years.

In addition one can look at the clusters used as a function of the ambient temperature repartition and frequency. The largest clusters ate the extreme ones and the choice of the extreme temperatures is finally well correlated because one has $24 \%$ of the data on the lowest temperature cluster - around $0^{\circ} \mathrm{C}, 30 \%$ of the data on the highest temperature cluster - around $25^{\circ} \mathrm{C}$. Even if the two middle temperatures $T_{2}$ and $T_{3}$ are more used than the others the difference of the frequency between each cluster is not significant. Thus every cluster has an important role. Table 1 displays the frequency of each cluster:

Table 1. Temperature clusters and multi-periods.

\begin{tabular}{lll}
\hline $\begin{array}{l}\text { Temperature } \\
\text { (clusters) }\end{array}$ & $\begin{array}{l}\text { Frequency (number } \\
\text { of time steps) }\end{array}$ & Percentage \\
\hline$T_{1}=0.5^{\circ} \mathrm{C}$ & 22793 & $23.64 \%$ \\
$T_{2}=8{ }^{\circ} \mathrm{C}$ & 28519 & $29.58 \%$ \\
$T_{3}=15^{\circ} \mathrm{C}$ & 28855 & $29.93 \%$ \\
$T_{4}=23^{\circ} \mathrm{C}$ & 16242 & $16.85 \%$ \\
\hline
\end{tabular}

\subsection{Energy Integration-Energy Recovery Technology}

The organic Rankine cycle is used as utility in the energy integration to recover the waste heat from the engine and to produce mechanical power for propulsion or for integrating the comfort demands of the vehicle. The steps of the organic Rankine cycle are well known and the transformations are summarized below:

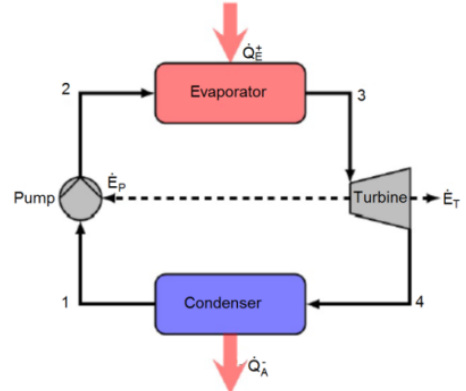

Figure 6. Rankine Cycle installation. 
The assumptions made for the implementation of the $\mathrm{RC}$ are:

- The working fluid is ammonia because it is considered as the most efficient fluid

- The efficiency of the turbine is $70 \%$

- The efficiency of the compressor is $80 \%$

- The evaporation temperature is determined by the engine cooling water outlet temperature and engine exhaust gases outlet temperature

- The condensation temperature is determined by the ambient temperature

- The values of $\Delta T_{\min } / 2$ are from the Table 2

Table 2. Delta T minimal for the energy integration.

\begin{tabular}{lc}
\hline Stream type & $\Delta T_{\min } / 2\left[{ }^{\circ} \mathrm{C}\right]$ \\
\hline Gas & 15 \\
Liquid & 5 \\
Evaporating & 2 \\
Condensing & 3 \\
\hline
\end{tabular}

The ORC cycle is sized with the application of the energy integration methodology exposed in Section 2.

Engine Characteristics. This study considers a small gasoline engine. The main characteristics are given in Table 4.

Streams definition. The energy integration targets the waste heat recovery from the engine and heating or cooling of the vehicle cabin. The integration concerns the mobility and the comfort service of the vehicle. The different streams and their general equations are listed below to construct the heat cascade:

- Cabin heating: from the ambient temperature to the desired temperature (if the cabin has to be heated). The optimal temperature for the comfort is $22^{\circ} \mathrm{C}$.

$\dot{Q}_{\text {cabin_heating }}^{+}=\dot{M}_{\text {air_cabin }} * c_{\text {pair }} *\left(T_{\text {desired }}-T_{\text {ext }}\right)$

- Cabin cooling: from the ambient temperature to the desired temperature (if the cabin has to be cooled down)

$\dot{Q}_{\text {cabin_heating }}^{+}=\dot{M}_{\text {air_cabin }} * c_{\text {pair }} *\left(T_{\text {ext }}-T_{\text {desired }}\right)$

- Engine water cooling:

$\dot{Q}_{\text {water }}^{+}=\dot{M}_{\text {water }} * c_{p \text { water }} *\left(T_{\text {water_outlet }}-T_{\text {watar_inlet }}\right)$

- Engine oil cooling

$\dot{Q}^{+}{ }_{\text {oil }}=\dot{M}_{\text {oil }} * c_{p_{\text {oil }}} *\left(T_{\text {oil }, \text { outlet }}-T_{\text {oil, inlet }}\right)$

- Exhaust cooling:

$\dot{Q}_{\text {exhaust }}^{+}=\dot{M}_{\text {exhaust }} * c_{p_{\text {exhaust }}} *\left(T_{\text {exhaust }, \text { oulet }}-T_{\text {ext }}\right)$

- ORC preheating:

$Q_{O R C_{\text {_ }} \text { preheating }}^{+}=\dot{M}_{\text {fluid }} *\left(h_{3}^{\prime}-h_{2}\right)$

- ORC evaporation:

$Q_{O R C_{\text {enaporatio }}}^{+}=\dot{M}_{\text {fluid }} *\left(h_{3}^{\prime \prime}-h_{3}^{\prime}\right)$

- ORC superheating:
$Q_{O R C_{\text {_superheating }}}^{+}=\dot{M}_{\text {fluid }}\left(h_{3}-h_{3}^{\prime \prime}\right)$

- ORC cooling:

$Q_{O R C_{-} \text {cooling }}^{+}=\dot{M}_{\text {fluid }}\left(h_{4}^{\prime \prime}-h_{4}\right)$

- ORC condensation:

$\dot{Q}_{O R C_{-} \text {condesnation }}^{+}=\dot{M}_{\text {fluid }}\left(h_{1}-h_{4}^{\prime \prime}\right)$

The streams and the utilities are defined in the Energy Integration module of the computational tool (Figure 1). The energy integration is a slave optimization problem, which uses a mixed integer nonlinear programming to be solved. The energy balance of the engine and the cabin is established and the heat cascade is defined. The internal combustion engine is a system with excess of heat and the Organic Rankine Cycle is selected as utility to recover the heat and convert it into mechanical power.

The energy integration methodology is based on the heat integration, which targets the maximum heat recovery in an energy system. The energy system is constituted from unitary processes exchanging heat between them. The approach consists in mapping all hot and cold streams in the system and displays the heat composite curve. Examples of the composites curves with the energy integration of ORC are given on the Figures 7 and 8.

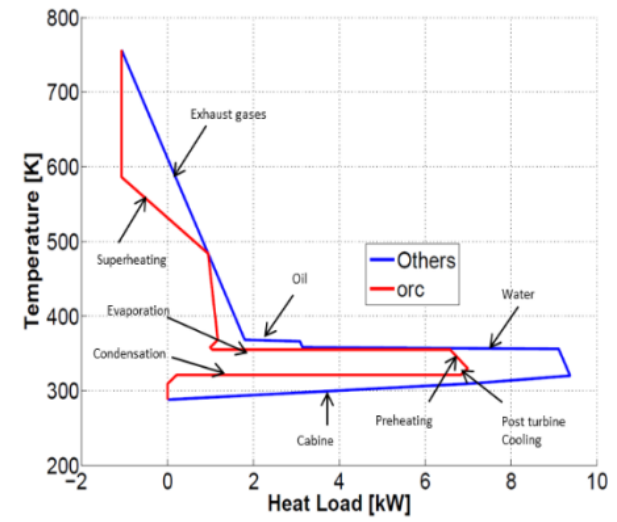

Figure 7. Energy integration on 2000 rpm 2 bar operating point.

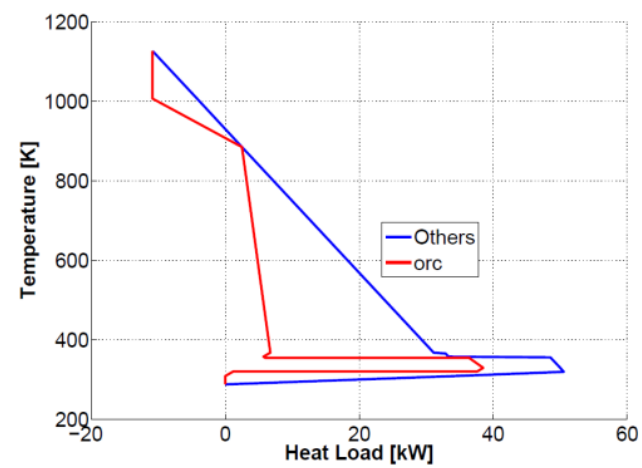

Figure 8. Energy integration on 5000 rpm 8 bar operating point.

The engine and cabin streams and the ORC streams are indicated on the Figure 7. For the engine low speed and low load point - $2000 \mathrm{rpm} 2$ bar of BMEP, the engine water circuit presents the most important potential of heat recovery $-5 \mathrm{~kW}$ and the exhaust gases are the second important heat source with a potential of $2.5 \mathrm{~kW}$ heat load. 
At high load and high rotation speed (Figure 8), the main heat source is the exhaust gases, which reach an important temperature of $1100 \mathrm{~K}$ and their heat recovery potential is $30 \mathrm{~kW}$. The water circuit is the second source for heat recovery, with $12 \mathrm{~kW}$ of heat load. One can conclude that the heat recovery potential and the order of importance of the two main heat sources depend on the operating point of the engine.

\subsection{ORC Performances Indicators and Cost}

The energy integration approach is extended on all operating points from the engine operating field. The performances indicators of the energy integration utility the ORC are presented on the next figures. The performances indicators are illustrated for the winter case and the gasoline engines. The dependence of the performances indicators of the energy integration of the ambient temperature will be studied in the next part. The performances indicators will be illustrated on the temperature clusters defined in the part 1 .

\subsubsection{Performances Indicators}

The net power in $\mathrm{kW}$ is the absolute value of the mechanical power, delivered by the Rankine cycle.

$$
\dot{P}_{n e t}=\left|\dot{P}_{\text {expansion }}\right|-\left|\dot{P}_{\text {pumping }}\right|
$$

Energetic efficiency: The energetic efficiency is here defined as the ratio of the net mechanical power output over the thermal energy available in the main hot sources - the engine exhaust gases and the water circuit), with a reference of the ambient temperature.

$$
\varepsilon=\frac{\dot{P}_{n e t}}{\dot{Q}_{\text {exhaut_gas }}+\dot{Q}_{\text {cooling_water }}}
$$

The available heat is the amount of energy present in the streams and depends on the engine operating point and the ambient temperature.

Exergetic efficiency: The exergetic efficiency is the ratio between the net power-work delivered by the ORC and the exergy- heat received by the ORC system.

$\eta=\frac{\dot{P}_{\text {net }}}{\dot{E}_{\text {exhaut_gas }}+\dot{E}_{\text {cooling_water }}}$

with

$$
\dot{E}_{\text {exhaust_gas }}=\int_{Q}\left(1-\frac{T_{a}}{T_{\text {exhaust_gas }}}\right) \delta \dot{Q}_{\text {exhaust_gas }}
$$

and

$\dot{E}_{\text {cooling_water }}=\int_{Q}\left(1-\frac{T_{a}}{T_{\text {cooling_water }}}\right) \delta \dot{Q}_{\text {cooling_water }}$

If one assumes a constant specific heat of the fluid constituting the heat source between its initial and final temperature ( $\mathrm{T}_{\text {in }}$ and $\mathrm{T}_{\text {out }}$ respectively), the initial form can be replaced by the expression below, using the logarithmic temperature difference.
$E_{x}=\left(1-\frac{T_{a}}{T_{L T D}}\right) * Q$, with $T_{L T D}=\frac{T_{\text {in }}-T_{\text {out }}}{\ln \frac{T_{\text {in }}}{T_{\text {out }}}}$

$\dot{E}_{\text {exhaust_gas }}=\int_{Q}\left(1-\frac{T_{a}}{T_{\text {exhaust_gas }}}\right) \delta \dot{Q}=$

$\dot{Q}_{\text {exhaust_gas }} *\left(1-\frac{T_{a}}{T_{\text {exhaust_gas }}}\right)$

$\dot{E}_{\text {cooling_water }}=\int_{Q}\left(1-\frac{T_{a}}{T_{\text {cooling_water }}}\right) \delta \dot{Q}_{\text {cooling_water }}=$
$\dot{Q}_{\text {cooling_water }} *\left(1-\frac{T_{a}}{\frac{T_{\text {cooling_water_in }}-T_{\text {cooling_water_out }}}{T_{\text {cooling_water_in }}}}\right)$
$\ln \frac{T_{\text {cooling_water_out }}}{T_{\text {coling }}}$

The thermodynamic optimization aims at maximizing the net power output. The other thermodynamic indicators the energetic efficiency and the exergetic efficiency are additionally used to characterize the thermodynamic behavior of the system. The cycle thermal efficiency - the energetic efficiency is an indicative parameter of the quality of the heat converted into power (Eq.(12)).

The different evaporation pressure varies the heat transferred to the power cycle. An increase in the evaporation pressure reduces the amount of heat transferred to the power cycle and the amount of heat rejected at the condenser. Figures 9, 10, 11 illustrate the ORC performances indicators on the global engine field.

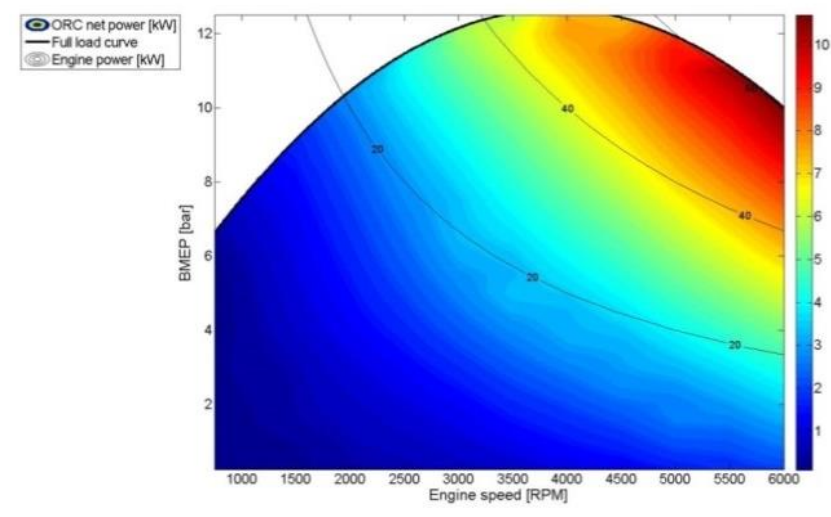

Figure 9. ORC net power on the gasoline engine operating field, $T_{\text {ext }}=0^{\circ} \mathrm{C}$.

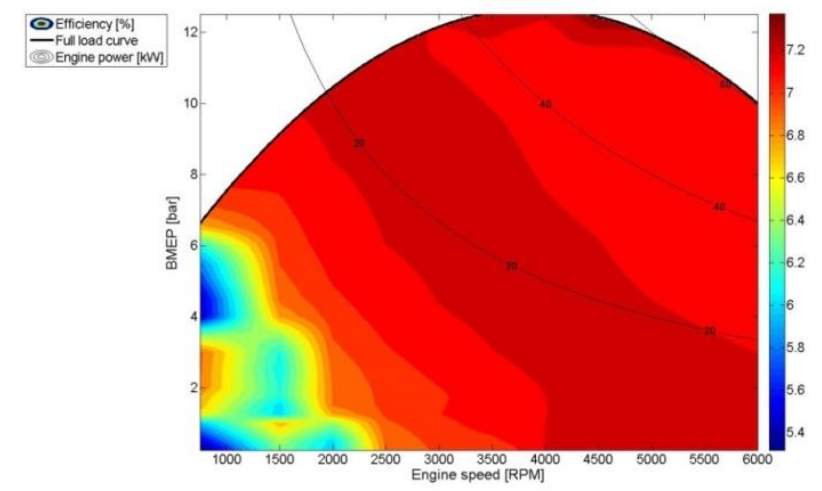

Figure 10. ORC energetic efficiency on the gasoline engine operating field, $T_{\text {ext }}=0^{\circ} \mathrm{C}$. 


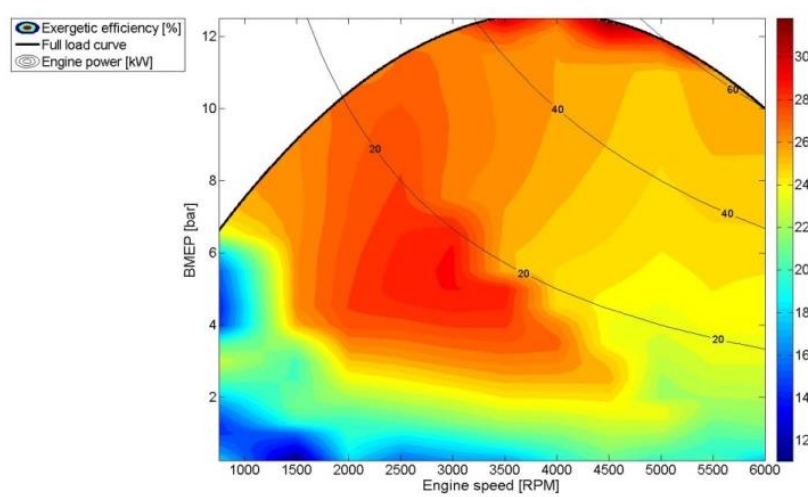

Figure 11. ORC exergetic efficiency on the gasoline engine operating field, $T_{\text {ext }}=0{ }^{\circ} \mathrm{C}$.

An optimum is obtained for the three parameters but for different pressure values. On the figures of the performances indicators on the gasoline engine is visible that the maximum power zone is different of the maximum energetic efficiency zone and the exergetic efficiency zone. The exergy map of the engine shows the zones with maximum heat recovery potential - the high speeds and the high loads zone, where the temperature of the exhaust gases is important. Thus the gasoline exergy efficiency is important - superior to $30 \%$. The high temperature water in the engine cooling circuit is an additional source, visible on the exergy maps, in the zone of low rotation speed and low loads. In case that the heat recovery is for free, because the heat in the exhaust gases and the water circuit is lost. In these two zones the ORC net power is maximized.

Economic model of the energy integration technology. The economic model for the components of the energy integration utility is based on estimations for the cost of the utility components are pump, turbine, and heat exchangers (condenser and evaporator). The economic model is related to the size of the components and the costs are minimized by the minimization of the ORC size. The equations for every component are coming from the cost analysis of parts already known and with a large scale application in the automotive industry. The reference elements for the pump and the heat exchangers are the components from the air cooling installation in the vehicle. For the turbine cost the engine turbo machines are benchmarked. The cost model is valuable for utilities with small size and installations producing between 5 and $50 \mathrm{~kW}$ of net power.

The basic equations and their applications on the studied diesel and gasoline engine are done. Thus one obtains an order of magnitude for the total utility cost in $€$, which is:

$$
\begin{aligned}
& \text { Cost }_{\text {utility }}=\text { Cost }_{\text {condenser }}+\text { Cost }_{\text {evaporator }}+\text { Cost }_{\text {compressor }} \\
& + \text { Cost }_{\text {turbine }} \text { Cost }_{\text {pipes }}+\text { Cost }_{\text {fluide }}
\end{aligned}
$$

\section{Pump:}

$$
C_{\text {pump }}=165+83 * P_{\text {pump }}\left(€, P_{\text {pump }} \text { in }[\mathrm{kW}]\right.
$$

The cost of the equipment is:

- For a gasoline engine at $T_{\text {ext }}=0^{\circ} \mathrm{C}: 178.53 €$

\section{Turbine:}

$$
C_{\text {turbine }}=15^{*} P_{\text {turbine }}-30
$$

with $P_{\text {turbine }}$ in $\mathrm{kW}$. The cost for the equipment is:

- $\quad$ For a gasoline engine at $T_{\text {ext }}=0^{\circ} \mathrm{C}: 134.14 €$
The cost equation of the turbine comes from the linear correlation between the power past through the turbo shaft of two turbo, mounted on serial gasoline engines. The power of the ORC is in the same range that the power passed through the turbo shaft.

\section{Heat exchangers: \\ Condenser:}

The cost equation (Figure 12) for the condenser is obtained from the linear correlation between the total exchange area and the cost for serial cross flow condensers, massively used in the vehicles. The technical data are available in the detailed specification of the condenser of serial vehicles.

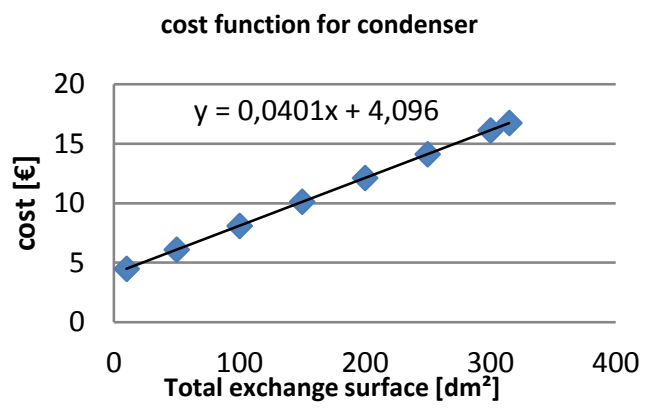

Figure 12. Cost function for condenser.

\section{Evaporator:}

The cost equation (Figure 13) for the evaporator is obtained from the linear correlation between the total exchange area and the cost for serial cross flow evaporator, massively used in the vehicles. The technical data are available in the detailed specification of the evaporator of serial vehicle.

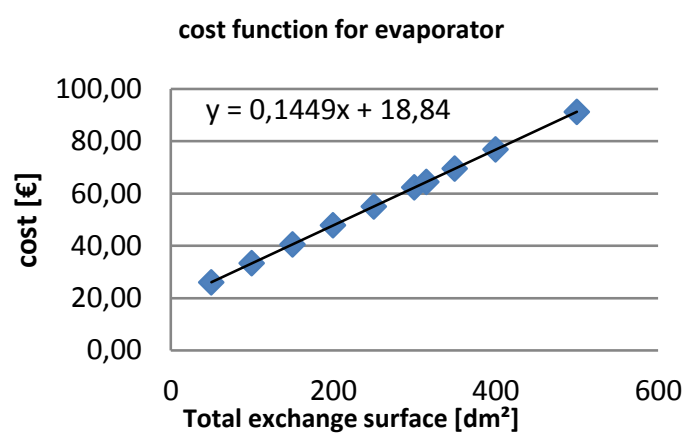

Figure 13. Cost function for evaporator.

The cost equation for the heat exchanger is:

$$
\begin{aligned}
& C_{H E N}=\left(0.0401 * A_{e x} * 0.5 * 100+4.096\right)+ \\
& \left(0.1449 * A_{e x} * 0.5 * 100+18.84\right)
\end{aligned}
$$

The factor 100 multiplies $A_{e x}$ to convert the total exchange area from $\mathrm{m}^{2}$ to $\mathrm{dm}^{2}$. The factor 0.5 is because of the assumption that the evaporator and the condenser have the same area.

The total cost of equipment is:

- For a gasoline engine at $T_{\text {ext }}=0^{\circ} \mathrm{C}: 49.10 €$

- The cost of the pipes and the fluid is considered constant and is presented in the Eqs. (22) and (23). 


$$
\begin{aligned}
& \text { Cost }_{\text {pipe }}=26 € \\
& \text { Cost }_{\text {fluid }}=10 €
\end{aligned}
$$

The total cost for the gasoline ORC with maximal power of $10 \mathrm{~kW}$ is $386.87 €$. This cost represents the technical cost and is based on estimations in the domain of small scale installations.

\subsection{ORC Net Power, Energetic and Exergetic Efficiency Maps}

The ORC net power maps are illustrated as a function of the ambient temperature.

\section{Cluster $\mathrm{T}=8^{\circ} \mathrm{C}$}

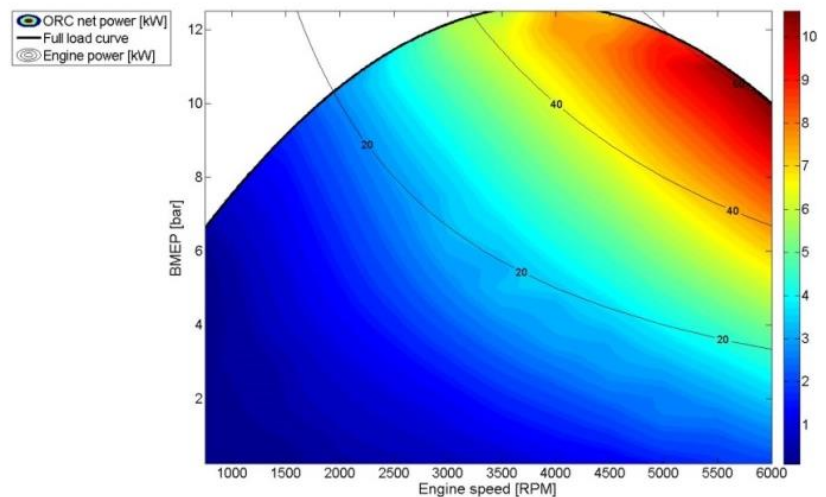

Figure 14. ORC net power on the gasoline engine operating field, $T_{\text {ext }}=8^{\circ} \mathrm{C}$.

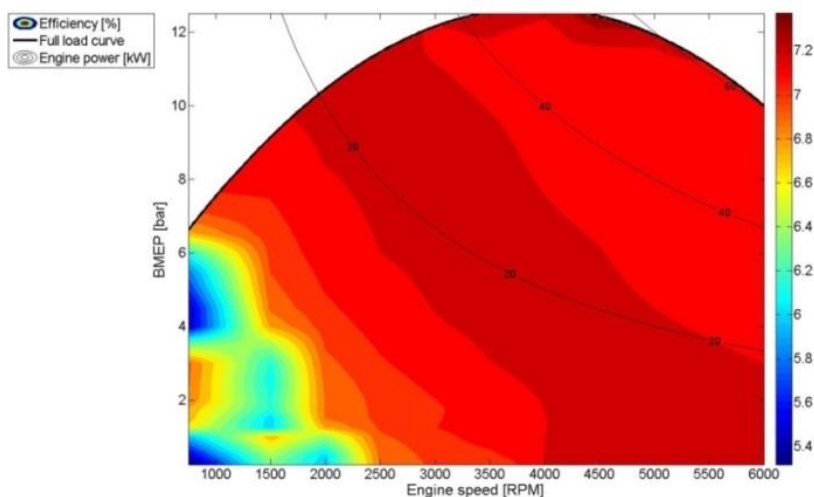

Figure 15. ORC energetic efficiency on the gasoline engine operating field, $T_{\text {ext }}=8^{\circ} \mathrm{C}$.

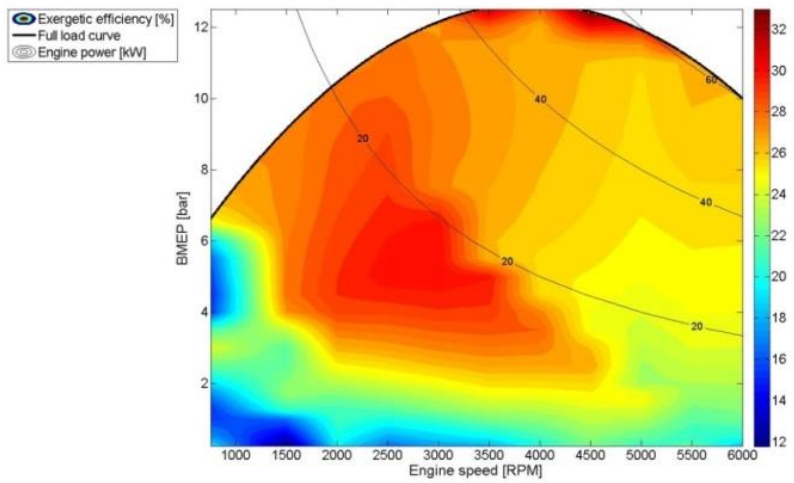

Figure 16. ORC exergetic efficiency on the gasoline engine operating field, $T_{\text {ext }}=8^{\circ} \mathrm{C}$.

\section{Cluster $\mathbf{T}=30^{\circ} \mathrm{C}$}

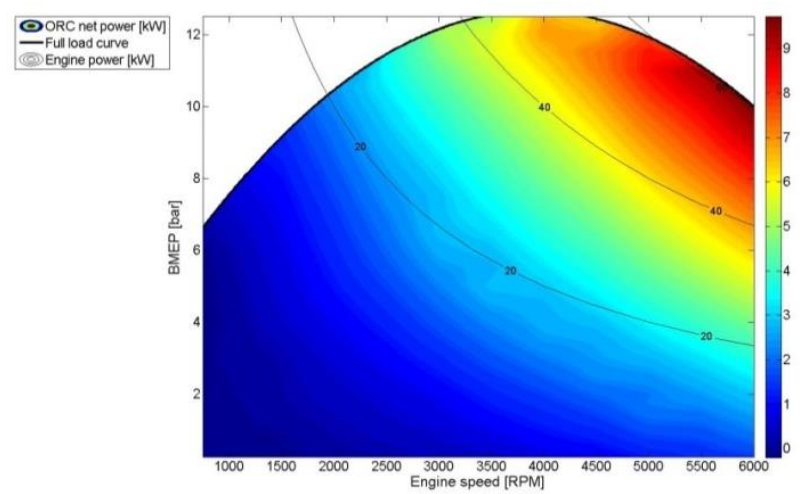

Figure 17: ORC net power on the gasoline engine operating field, $T_{\text {ext }}=30^{\circ} \mathrm{C}$.

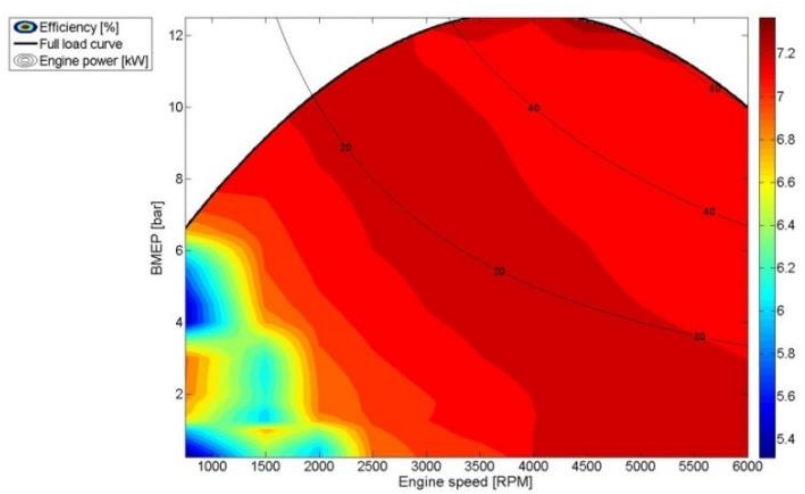

Figure 18: ORC energetic efficiency on the gasoline engine operating field, $T_{e x t}=30^{\circ} \mathrm{C}$.

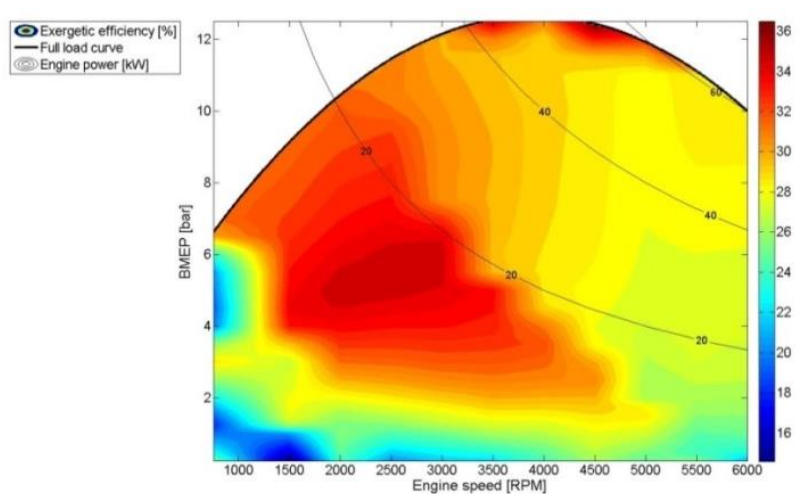

Figure 19: ORC exergetic efficiency on the gasoline engine operating field, $T_{\text {ext }}=30^{\circ} \mathrm{C}$.

The ORC net power output decreases with the ambient temperature increase. The heat pump is present in the energy integration when $T_{\text {ext }}>T_{\text {desired }}$ and the power takes into account the power needed for the heat pump compressor and the cooling of the cabin. For the summer case with $T_{\text {ext }}=30^{\circ} \mathrm{C}$ one can notice that the zone under 20 $\mathrm{kW}$ of the engine is representing $1 \mathrm{~kW}$ of energy recovery.

From the energetic efficiency map one can notice that the energetic efficiency map stays constant on the engine field. The maximum efficiency is $8 \%$ and according to the cycle design is located on the power band between $15 \mathrm{~kW}$ and $30 \mathrm{~kW}$. The cycle efficiency is not considering the ambient temperature (Eq. (12)).

From the exergetic efficiency map on can notice that the exergetic efficiency increases with the increasing external temperature. The maximum is in evolution from $30 \%$ when 
$T_{e x t}=0^{\circ} \mathrm{C}$ to 36 when $T_{e x t}=30^{\circ} \mathrm{C}$. The heat is multiplied by the Carnot Factor, which decreases with the $T_{\text {ext }}$ increase. The exergy of the heat source than decreases and the exergetic efficiency increases (Eqs. (13)-(18)).

\subsection{Heat Recovery Simulation Results on a Vehicle}

In the previous section net power and efficiency maps were created for an organic Rankine Cycle integrated on a 1.2 liter gasoline engine. These maps are now put to use as they are fitted into the quasi-static vehicle simulation model. Simulations are run for the normalized new European driving cycle (NEDC) on a pure thermal powertrain type. The vehicle used for this simulation is considered with a mass of $1100 \mathrm{~kg}$ and is equipped with a 1.21 gasoline engine and a manual gear box. Vehicle characteristics are given in Table 5. The ORC is considered as extension of the already existing air-conditioning system in the vehicles. The additional component is the expansion turbine. The heat exchangers and the pump already exist and the ORC components are considered to have similar weight. The additional weight related to the small size turbine is considered law and not impacting the total mass of the vehicle. The limitations of the ORC installation are the acceptable size of the heat exchangers. They should be compact and possible for integration in the vehicle. Table 3 summarizes the results.

Table 3. Results of the ORC integration on a thermal powertrain: $P_{M A X, O R C}$ maximum net power reached by the ORC; E: energy output during the cycle; $\eta_{p t}$ : powertrain efficiency in traction; $\eta_{p t, O R C}$ : powertrain efficiency taking into account the ORC net power; Delta $\eta$ efficiency improvement.

\begin{tabular}{lclllll}
\hline Cycle & $\begin{array}{c}T_{\text {ext }} \\
{\left[{ }^{\circ} \mathrm{C}\right]}\end{array}$ & $\begin{array}{l}P_{\text {MAX }, \text { ORC }} \\
{[\mathrm{kW}]}\end{array}$ & $\begin{array}{l}\mathrm{E} \\
{[\mathrm{kWh}]}\end{array}$ & $\begin{array}{c}\eta_{p t} \\
{[\%]}\end{array}$ & $\begin{array}{c}\eta_{p t, O R C} \\
{[\%]}\end{array}$ & $\Delta \eta$ \\
\hline NEDC & 0 & 7.22 & 0.28 & 18.50 & 26 & 7.50 \\
& & & & & & \\
NEDC & 30 & 4.20 & 0.14 & 18.50 & 21.30 & 2.80
\end{tabular}

The maximal benefit of the heat recovery technology integration of $7.5 \%$ on the powertrain efficiency is obtained for the lowest external temperature of $0^{\circ} \mathrm{C}$. The powertrain efficiency improvement is reduced with the increasing external temperature and for $\mathrm{T}_{\mathrm{ext}}=30^{\circ} \mathrm{C}$. Thus the improvement is $2.8 \%$. The ORC efficiency is sensitive on the external temperature. The lowest improvement of $2.8 \%$ is close to the simulation errors but could be accepted because at least the comfort service in the cabin for cooling is be satisfied and this will not cost an additional fuel to drive the air-conditioning system.

\section{Conclusion}

This article presents a study of the waste heat recovery potential of an ORC for a small gasoline combustion engine. The performances indicators of the waste heat recovery system are introduced. The external temperature variation is represented as a typical multi-periods characteristic on a simplified clustering way. The influence of the typical external temperature on the waste heat recovery performances indicators is studied. An economic model for the technical cost estimation of the ORC technology is presented. This model is done for small scale waste heat recovery systems and is based on costs of components already known in the automotive industry. The objective of its usage is simply to fixe some orders of magnitudes in the domain of the small scale waste heat recovery installations.

The conclusion on the main performance indicator - the delivered net power - is that the ORC net power output decreases with the ambient temperature increase. Thus the fuel saving contribution of the ORC is sensitive on the ambient temperature. The maximal fuel consumption benefit of the waste heat recovery for a small gasoline engine is $7 \%$ for the winter case. The benefit is reduced to around $3 \%$ for the summer case.

\section{Acknowledgements}

The authors thank EPFL for the research support.

\section{Appendix}

Table 4. Internal combustion engine characteristics.

\begin{tabular}{ll}
\hline & Gasoline \\
\hline Displacement & 1.21 \\
Respiration & Natural Aspirated \\
Rated Power [kW] & 60 \\
Number of cylinders & 3 \\
Max Toque [Nm] & 120 \\
Max Rotation speed [rpm] & 6000 \\
\hline
\end{tabular}

Table 5. Vehicle characteristics.

\begin{tabular}{ll}
\hline Parameters & Value \\
\hline Mass [kg] & 1100 \\
Engine & Gasoline \\
Displacement volume [1] & 1.2 \\
Gear box & Manual \\
Gear ratios [-] & 6 \\
\hline
\end{tabular}

$\begin{array}{lll}\begin{array}{c}\text { Nomenclature } \\ \text { Abbreviation }\end{array} & \text { Unit (if applicable) } & \text { Description } \\ \dot{E}_{P} & \mathrm{~kW} & \text { Pump power } \\ \dot{E}_{T} & \mathrm{~kW} & \text { Turbine power } \\ \dot{Q}_{E}^{+} & \mathrm{kW} & \text { Heat load evaporation } \\ \dot{Q}_{A}^{-} & \mathrm{kW} & \text { Heat load condensation } \\ \dot{Q}_{X} & \mathrm{~kW} & \text { Heat load for x element } \\ \dot{M}_{x} & \mathrm{~kg} / \mathrm{s} & \text { Flow of the x fluid } \\ \dot{P}_{n e t} & \mathrm{~kW} & \text { Net power output } \\ \dot{P}_{\text {expansion }} & \mathrm{kW} & \text { Expansion power } \\ \dot{P}_{\text {pump }} & \mathrm{kW} & \text { Pumping power } \\ h_{x} & \mathrm{~J} / \mathrm{kg} & \text { Enthalpy of x } \\ \text { MER } & - & \text { transformation } \\ T_{a} & { }^{\circ} \mathrm{C} & \text { Minimum energy } \\ T_{L T D} & - & \text { requirement } \\ C_{x} & € & \text { Ambient temperature } \\ & & \text { Logarithmic temperature } \\ & \text { difference } \\ \text { Cost of x element }\end{array}$




\section{References}

[1] J. A. Caton, "The thermodynamic characteristics of high efficiency, internal-combustion engines," Energy Conversion and Management, 58, 84-93, 2012.

[2] J.P. Liu, J.Q. Fu, C.Q. Ren, L.J. Wang, Z.X. Xu, B.L. Deng, "Comparison and analysis of engine exhaust gas energy recovery potential through various bottom cycles," Applied Thermal Engineering, 50, 1219-1234, 2013.

[3] S. Bari, S. N. Hossain, Waste heat recovery from a diesel engine using shell and tube heat exchanger, Applied Thermal Engineering, 61, 355-363, 2013.

[4] Ch. Sprouse III, Ch. Depcik, Review of organic Rankine cycles for internal combustion engine exhaust waste heat recovery, Applied Thermal Engineering, 51, 711$722,2013$.

[5] D. Jung, S. Park, K. Min, "Selection of appropriate working fluids for Rankine cycles used for recovery of heat from exhaust gases of ICE in heavy-duty series hybrid electric vehicles," Applied Thermal Engineering, 81, 338-345, 2015.

[6] G. Li, "Organic Rankine cycle performance evaluation and thermoeconomic assessment with various applications part I: Energy and exergy performance evaluation," Renewable and Sustainable Energy Reviews, 53, 477-499, 2016.

[7] S.Quoilin, S. Declaye, B. F. Tchanche, V. Lemort, "Thermo-economic optimization of waste heat recovery Organic Rankine Cycles," Applied Thermal Engineering, 31, 2885-2893, 2011.

[8] Z. Dimitrova, F. Maréchal, "Energy integration study on a hybrid electric vehicle energy system, using process integration techniques," Applied Thermal Engineering, 91, 834-847, 2015.

[9] Z. Dimitrova, P. Lourdais, F. Maréchal, "Performance and economic optimization of an organic Rankine cycle for a gasoline hybrid pneumatic powertrain," Energy, 86, 74-588, 2015.

[10] J. J. Klemeš, Process Integration: An Introduction, In Woodhead Publishing Series in Energy, edited by Jiři J. Klemeš, Woodhead Publishing, 2013, Pages 3-27, Handbook of Process Integration (PI), ISBN 9780857095930,

http://dx.doi.org/10.1533/9780857097255.1.3.

[11] B. Linnhoff, E. Hindmarsh, "The pinch design method for heat exchanger networks," Chemical Engineering Science, 38, 745-763, 1983.

[12] P.S. Varbanov, Basic Process Integration Terminology, In Woodhead Publishing Series in Energy, edited by Jiř́ J. Klemeš, Woodhead Publishing, 2013, Pages 28-78, Handbook of Process Integration (PI), ISBN 9780857095930, http://dx.doi.org/10.1533/9780857097255.1.28.

[13] M. Bendig, F. Maréchal, D. Favrat,- "Defining "Waste Heat" for industrial processes," Applied Thermal Engineering 61, 134-142, 2013.

[14] S. Fazlollahi, F. Maréchal, "Multi-objective, multiperiod optimization of biomass conversion technologies using evolutionary algorithms and mixed integer linear programming (MILP)," Applied Thermal Engineering, 50, 1504- 1513, 2013.

[15] E. Peduzzi, L. Tock, G. Boissonet, F. Maréchal"Thermo-economic evaluation and optimization of the thermo-chemical conversion of biomass into methanol," Energy 58, 9-16, 2013.

[16] Z. Dimitrova, F. Maréchal, "Environomic design of vehicle energy systems for optimal mobility service," Energy, http://dx.doi.org/10.1016/j.energy.2014.09.019

[17] Z. Dimitrova, F. Maréchal, "Environomic design of vehicle integrated energy systems- application on a hybrid electric vehicle energy system," CET, doi:10.3303/CET1439080. 